\title{
Surface modification of CNTs with N-doped carbon: an effective way of enhancing its performance in supercapacitors
}

\author{
Marta Sevilla, ${ }^{\text {a }}$ Linghui Yu, ${ }^{\mathrm{b}}$ Li Zhao, ${ }^{\mathrm{c}}$ Conchi O. Ania, ${ }^{\mathrm{a}}$ Maria-Magdalena Titiricic*d \\ a Instituto Nacional del Carbón (CSIC), P. O. Box 73, Oviedo 33080, Spain. E-mail: \\ martasev@incar.csic.es \\ ${ }^{\mathrm{b}}$ Max-Planck Institute of Colloids and Interfaces, Am Muhlenberg 1, 14476, Potsdam, Germany \\ ${ }^{c}$ National Center for Nanoscience and Technology, Zhongguancun, 100190 Beijing, P.R. China \\ ${ }^{\mathrm{d}}$ Queen Mary, University of London, School of Engineering and Materials Science, Mile End \\ Road, London, E1 4NS, United Kingdom. E-mail: m.m.titirici@qmul.ac.uk
}

\begin{abstract}
Carbon nanotubes have been successfully coated with a N-doped carbon layer via hydrothermal carbonization in the presence of a nitrogen-containing carbohydrate, i.e. glucosamine hydrochloride. By controlling the amount of glucosamine added, it was possible to tune the $\mathrm{N}$ content of the composites N-doped carbon/CNT between $1.8-2.5 \mathrm{wt} \%$. The prepared composites exhibited superior supercapacitor performance in comparison to bare CNTs even though they possess lower textural properties. Thus, a 3- to 4-fold increase in specific capacitance per surface area was registered at low current densities and sweep rates, and a 2fold increase in energy density, while keeping the power density. Besides, the composites possess superb long-term stability, losing only 4-6\% of specific capacitance after 10000 cycles at $10 \mathrm{~A} \mathrm{~g}^{-1}$.
\end{abstract}

Keywords: N-doping, composite, hydrothermal carbonization, energy storage, supercapacitor 


\section{Introduction}

Most of the research efforts today are dedicated to the discovery of novel, sustainable and innovative materials with applications in renewable energy. Regarding efficient energy storage devices, supercapacitors offer a very promising approach for fast energy storage of the excess electrical energy generated from renewable resources such as sun, wind or water. Supercapacitors started gaining a significant importance in areas such as portable electronics, hybrid electric vehicles, and stand-by power systems. ${ }^{1}$

The performance of these devices is intimately linked with the physical and chemical properties of their constituent electrode materials. Recently, there has been a great deal of research efforts dedicated to improving the performance of these devices. Early studies focused on the development of high surface area porous carbons ${ }^{2}$, which can store energy in the double layer, formed at the interface between the micropores and the electrolyte. Later, the pseudocapacitance effect has been explored. Pseudocapacitance is based on redox reactions between the carbon electrode's functional groups (i.e. oxygen, nitrogen) and the electrolyte. ${ }^{3}$ Although most of the porous materials exhibit large capacitances due to a combination of double layer and pseudocapacitance, their electrical conductivity suffers from a decrease with increasing porosity and functional groups due to non-compatibility of conductive pathways with functional groups. 4

To further enhance the energy density and specific power of capacitors, the strategy of utilizing electrode materials possessing the right combination of conductivity, porosity and pseudocapacitance is vital.

As previously mentioned, functional groups have been previously introduced into carbons to achieve such pseudocapacitance phenomena. In particular, nitrogen doping seems to be the most promising method for enhancing the capacity, ${ }^{5}$ surface wettability of the materials, ${ }^{6}$ and electronic conductivity while maintaining a good cycling performance.

There are several ways of introducing nitrogen heteroatoms in carbon materials either based on post-modification with N-containing precursors such as ammonia gas ${ }^{7}$ or "in situ" functionalization. ${ }^{8}$ Regarding the second category, Titirici et al. recently reported a sustainable method to produce high surface area nitrogen doped carbons based on hydrothermal carbonization of glucosamine followed by chemical activation. ${ }^{9}$ These materials had a good performance when used as electrodes in supercapacitors due to the right combination of microporosity (double layer storage) and nitrogen heteroatoms (pseudocapacitance). However the conductivity of these materials was not exceptional, leading to a poor power capacity.

Carbon nanotubes, due to their unique pore structure, superior electrical properties, and good mechanical and thermal stability, have attracted a great deal of attention for supercapacitor electrode applications. Carbon nanotubes have been previously explored in supercapacitors 
applications due to their exceptional physical properties such as electronic conductivity. ${ }^{1} \mathrm{CNTs}$ are usually regarded as the choice of a high-power electrode material because of their good electrical conductivity and readily accessible surface area. Moreover, their high mechanical resilience and open tubular network make them a good support for active materials. The energy density is, however, a concern due to their relatively small specific surface area as compared to ACs. ${ }^{10}$ Of greater importance is the difficulty in retaining the intrinsic properties of individual CNTs on a macroscopic scale ${ }^{11}$ and the high purity and electrolyte-dependent capacitance performance. $^{12}$ ENREF 12 CNT have been previously used for many applications in combination with different polymeric materials, among which conductive polymers such as polypyrrole have also been employed. ${ }^{13}$ ENREF 13 Composites of CNTs and N-carbon obtained from polyacrylonitrile or melamine/formaldehyde have been prepared by Lota et al. by physical mixing of both components, followed by carbonization. ${ }^{14,15}$ For the former composites, surfacearea normalized capacitances of $\sim 22-32 \mu \mathrm{F} \mathrm{cm} \mathrm{cm}^{-2}$ (2-electrode cell) were obtained for nitrogen contents of $7-14 \mathrm{wt} \%$, whereas for the latter surface-area normalized capacitances of $\sim 24-64$ $\mu \mathrm{F} \mathrm{cm}{ }^{-2}$ (2-electrode cell) for $\mathrm{N}$ content $\geq 9.2$ at $\%$. Very recently, Jin and co-workers ${ }^{16}$ and BaiGang and co-workers ${ }^{17}$ followed a more complicated approach for the preparation of composites $\mathrm{N}$-carbon/CNT, which is based on the carbonization of a N-rich polymer that has been previously coated onto the CNTs. In both cases, polyaniline was selected as N-rich polymer, leading to $\mathrm{N}$ contents in the $\sim 5-10 \mathrm{wt} . \%$ and $\sim 7-9 \mathrm{wt} . \%$ respectively. The electrochemical performance was analyzed using a three-electrode configuration, registering surface-area normalized capacitances of $\sim 60-100 \mu \mathrm{F} \mathrm{cm}{ }^{-2} .{ }^{16}$

Glucosamine is a sustainable and low cost precursor for nitrogen doped carbons as it can be easily produced from chitin, which is extracted from food waste (i.e. crustacean shells). Its use is therefore more advantageous than the usual $\mathrm{N}$-dopants, such as polypyrrole, polyacrylonitrile, polyaniline or melamine. Here, we wanted to explore for the first time the potential of this precursor for supercapacitors applications in combination with a conductive carbon matrix, i.e. carbon nanotubes.

Hydrothermal carbonization is also called the "sol-gel" approach to carbon materials and it is a very suitable method to produce various morphologies of carbon materials. ${ }^{18}$ This also includes coating of various pre-formed nanostructures. ${ }^{19} \mathrm{We}$ have used preformed carbon nanotubes and coated them with a thin layer of glucosamine-derived hydrothermal carbons and studied the performance of the resulting carbon-carbon composite in supercapacitors. A 3- to 4-fold increase in specific capacitance per surface area was registered at low current densities and sweep rates, and a 2-fold increase in energy density, while keeping the power density. Besides, the composites possess superb long-term stability, losing only 4-6\% of specific capacitance after 10000 cycles at $10 \mathrm{~A} \mathrm{~g}^{-1}$. 


\section{Experimental section}

\section{Surface modification of CNTs with $N$-doped carbon}

The composites were prepared via N-doped carbon coating onto carbon nanotubes (Baytubes ${ }^{\circledR}$ ) by hydrothermal treatment of glucosamine hydrochloride (GA, Fluka), used as a nitrogen source. Firstly, $1.2 \mathrm{~g}$ or $1.8 \mathrm{~g}$ of GA was dissolved into $15 \mathrm{~mL}$ of deionized water in a glass autoclave inlet. To this solution, $0.5 \mathrm{~g}$ of CNTs were added and dispersed by stirring for 30 minutes and then ultrasonication for 10 minutes. The glass inlet was then sealed into a Teflonlined, stainless steel autoclave and kept at $180^{\circ} \mathrm{C}$ for $24 \mathrm{~h}$. The resultant powders were washed with deionized water several times, dried under vacuum at $80{ }^{\circ} \mathrm{C}$ overnight, and finally calcined at $900{ }^{\circ} \mathrm{C}$ under $\mathrm{N}_{2}$ for $4 \mathrm{~h}$ to get the product. The final calcined samples are denoted as $\mathrm{N}$ CNT1 (1.2 $\mathrm{g}$ of GA derived) and N-CNT2 (1.8 $\mathrm{g}$ of GA derived).

\section{Characterization}

Scanning electron microscopy (SEM) images were recorded on a Gemini Leo-1550 instrument. Transmission electron microscopy (TEM) was carried out with a Carl Zeiss Omega 912X at an acceleration voltage of $120 \mathrm{kV}$. Elemental analysis data were acquired using a Vario E1 elemental analyzer. $\mathrm{N}_{2}$ adsorption analysis was performed on a QUADRASORB SI/MP (Quantachrome Instruments) at $77.4 \mathrm{~K}$; prior to adsorption measurement, the samples were degassed at $150^{\circ} \mathrm{C}$ for $20 \mathrm{~h}$. Brunauer-Emmett-Teller (BET) method and Quenched Solid Density Functional Theory (QSDFT, equilibrium model, assuming slit-shaped pore geometry) were used for the surface area and pore size distribution (PSD) determination using $\mathrm{N}_{2}$ adsorption data. X-ray photoelectron spectroscopy (XPS) was carried out on a Specs spectrometer, using $\mathrm{Mg} \mathrm{K \alpha}(1253.6 \mathrm{eV})$ radiation from a double anode at $150 \mathrm{~W}$. Binding energies for the high resolution spectra were calibrated by setting $\mathrm{C} 1 \mathrm{~s}$ to $284.6 \mathrm{eV}$ and a Shirley background was used for peak deconvolution. The hydrophobicity of the samples was determined using their affinity to adsorb vapors of different polarity. Predetermined amounts of dry samples were exposed either to water and benzene vapors in air-tight environments for 24 hours at room temperature. The amounts adsorbed were measured gravimetrically.

\section{Electrochemical tests}

Electrodes were prepared by mixing $90 \mathrm{wt} \%$ of active material with $10 \mathrm{wt} \%$ of polytetrafluoroethylene (PTFE) binder (Aldrich, $60 \mathrm{wt} \%$ suspension in water). The electrochemical measurements were performed in a two- and a three-electrode (2E and $3 \mathrm{E}$, respectively) Swagelok ${ }^{\mathrm{TM}}$ type cells. Electrochemical capacitors were built using two carbon electrodes of comparable mass $(3-5 \mathrm{mg})$ and thickness $(250-300 \mu \mathrm{m})$, electrically isolated by 
glassy fibrous separator. Gold current collectors were used with $1 \mathrm{M} \mathrm{H}_{2} \mathrm{SO}_{4}$ as electrolyte. The electrochemical characterization was performed using a computer controlled potentiostat (Biologic VMP3 multichannel generator). Cyclic voltammetry was conducted between 0 and $0.8 \mathrm{~V}$ at sweep rates ranging from 1 to $100 \mathrm{mV} \cdot \mathrm{s}^{-1}$. The specific gravimetric capacitance of a single-electrode evaluated from data obtained in the 2-cell configuration, $C_{2 E, C V}^{s p}\left(\mathrm{~F} \mathrm{~g} \mathrm{~g}^{-1}\right)$, was calculated from the area of the voltammograms by means of the formula:

$$
C_{2 E, C V}^{s p}=\frac{\int \mathrm{IdV}}{\nu \cdot \mathrm{m} \cdot \Delta \mathrm{V}}
$$

where $I=$ current (A), $v=$ scan rate $(\mathrm{V} / \mathrm{s}), \Delta V=$ voltage window $(\mathrm{V})$, and $m=$ mass (grams) of carbon material in the working electrode.

Galvanostactic charge/discharge cycling was also performed in the $0-0.8 \mathrm{~V}$ range, at current densities in the $0.05-20 \mathrm{~A} \mathrm{~g}^{-1}$ range, based on the active mass of a single electrode. The specific gravimetric capacitance of a single-electrode determined from the galvanostatic cycles, $C_{2 E, G A}^{s p}\left(\mathrm{~F} \mathrm{~g}^{-1}\right)$, was calculated by means of the formula:

$$
C_{2 E, G A}^{s p}=\frac{2 \mathrm{I}}{(\mathrm{dV} / \mathrm{dt}) \cdot \mathrm{m}}
$$

where $d V / d t=$ slope of the discharge curve $\left(\mathrm{V} \mathrm{s}^{-1}\right)$.

Experiments were also carried out in three-electrode cells, using a graphite rod as counter electrode and $\mathrm{Hg} / \mathrm{Hg}_{2} \mathrm{SO}_{4}$ as the reference electrode. The corresponding specific gravimetric capacitance of a single electrode evaluated from data obtained in a three-electrode cell configuration, $C_{3 E}^{s p}\left(\mathrm{~F} \mathrm{~g}^{-1}\right)$, was also evaluated.

\section{Results and Discussion}

\section{Chemical and structural characterization}

Scanning electron microscopy (SEM) and transmission electron microscopy (TEM) were first employed to investigate the morphology of the original CNTs and the N-doped carbon / CNT composites. Figure $1 \mathrm{a}$ and $\mathrm{d}$ show the SEM and TEM images of the original CNTs, characterized by a flexible and bended structure and an outer diameter mainly between $\sim 5$ and $25 \mathrm{~nm}$. Figure $1 \mathrm{~b}$ shows the SEM image of N-CNT1 sample. No significant difference is observed between this sample and the original CNTs. HTC of biomass might result in discrete particles ${ }^{20-23}$ rather than coating HTC product onto CNTs. Here we did not find discrete particles but only CNTs, demonstrating that the HTC product formed along the outer surface of 
CNTs during HTC. The SEM image of N-CNT2, Figure 1c, shows that some parts of the CNTs become thicker and rougher due to increased amount of $\mathrm{N}$-doped carbon on the surface. However, most parts of N-CNT2 have similar morphology to the original CNTs, which is also confirmed by TEM analysis (Figures 1d and 1e). These microscopy characterizations demonstrate that our method can easily coat the nanotubes with a $\mathrm{N}$-doped carbon layer, and achieve thereby surface modified CNTs. The nitrogen contents, as determined by elemental analysis, are $1.8 \%$ and $2.5 \%$ for N-CNT1 and N-CNT2, respectively. An insight on the Nmoieties incorporated on the $\mathrm{N}$-doped carbon layer was provided by X-ray photoelectron spectroscopy. The N 1s core level spectrum of N-CNT2 is deconvoluted in Figure 2. Two main contributions are identified at 398.3 and $400.8 \mathrm{eV}$, which correspond respectively to pyridinic-N (39.5\%) and quaternary-N (58 \%), and a minor peak at $403 \mathrm{eV}$, which is attributed to N-oxides of pyridine-N. ${ }^{24,25}$ The weight ratio N/C is 0.026 for the bulk (elemental analysis) and 0.037 at the surface (XPS), which agrees with a surface coating of the CNTs with N-doped carbon.

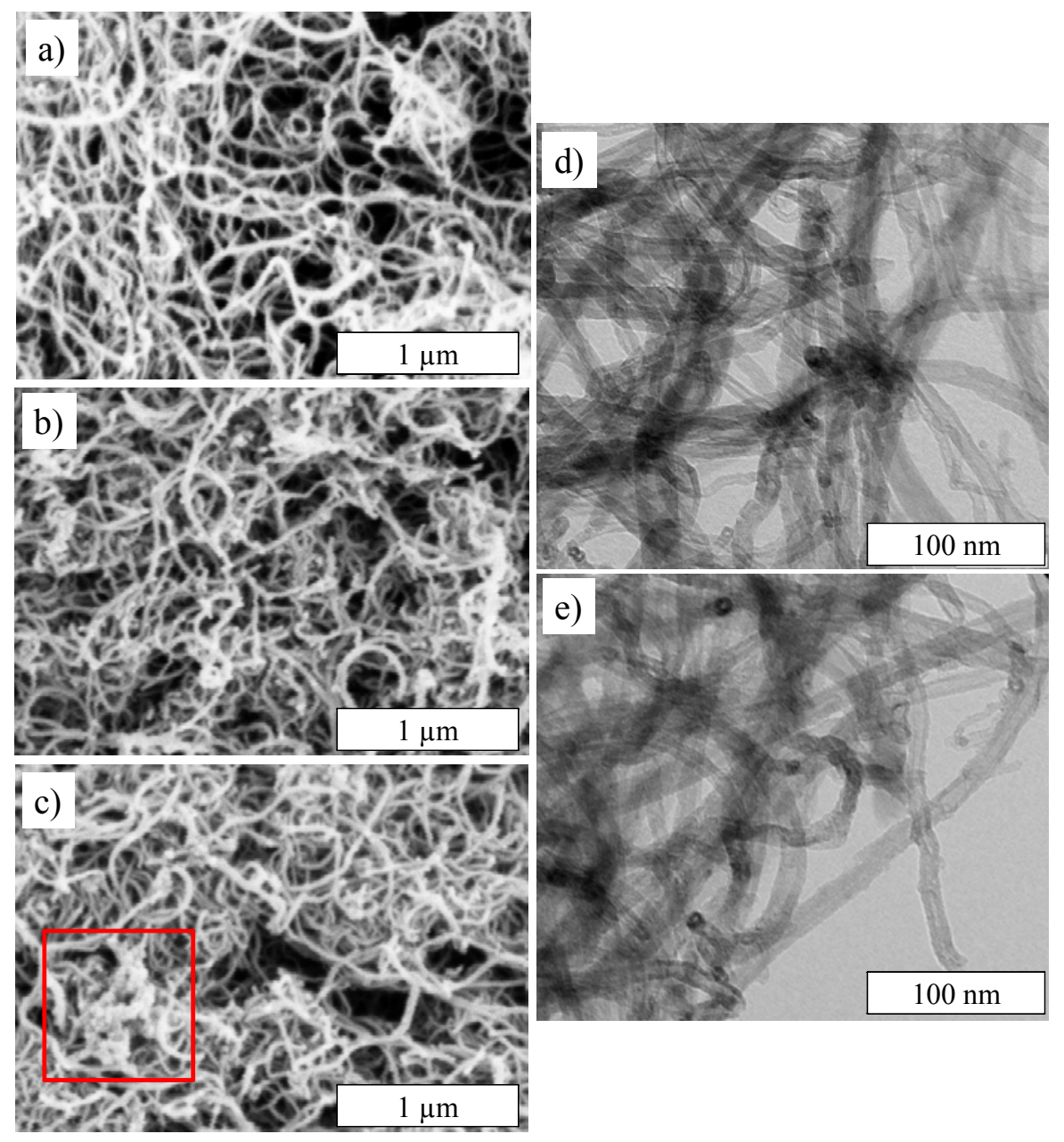

Figure 1. SEM images of (a) the original CNTs, (b) N-CNT1, and (c) N-CNT2. The CNTs become significant thicker and rougher in the red box in (c). And TEM images of (d) the original CNTs, and (e) N-CNT2. 


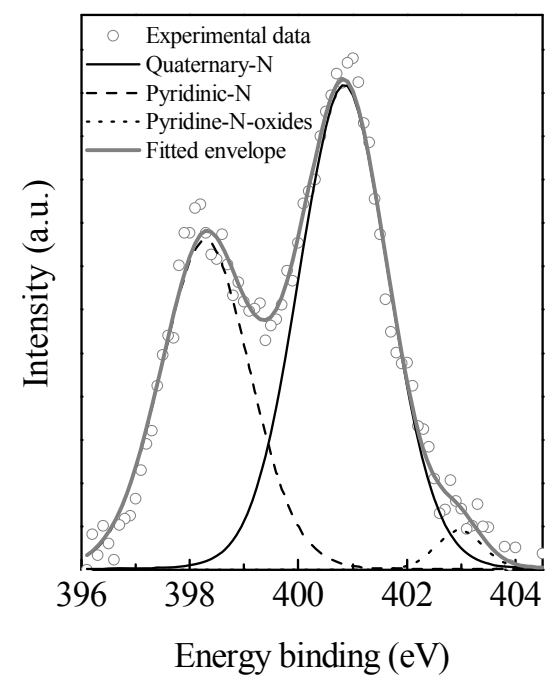

Figure 2. XPS N 1s core level spectrum of N-CNT2.

To characterize the porosity and surface area of the two synthesized materials as well as the original CNTs, $\mathrm{N}_{2}$ adsorption measurements were performed. The isotherms (Figure 3a) of all the materials show a large capillary condensation at relative pressures higher than 0.85-0.9, caused by adsorption in interparticle voids created by the entanglement of the CNTs bundles. The PSDs of the materials show mesopores ranging mainly from 2 to $20 \mathrm{~nm}$, that correspond to the inner cavities of the nanotubes, as also evidenced by TEM (Figures 1d and 1e). Pores of larger sizes account for the interparticle voids, as mentioned above. The PSDs of the modified samples remain similar to that of pristine CNTs, confirming the surface coating with a N-doped carbon layer. Also, the N-carbon coating led to a slight decrease in the BET surface area -with values going from $272 \mathrm{~m}^{2} \mathrm{~g}^{-1}$ for the original nanotubes to $200 \mathrm{~m}^{2} \mathrm{~g}^{-1}$ for N-CNT1, and 172 $\mathrm{m}^{2} \cdot \mathrm{g}^{-1}$ for N-CNT2, as a result of the lack of porosity of the N-doped coating layer. The detailed porosity data and surface areas are summarized in Table 1.

Table 1. Main porosity parameters of the raw CNTs and N-Doped Carbon / CNTs composites evaluated from $\mathrm{N}_{2}$ adsorption data at $77 \mathrm{~K}$.

\begin{tabular}{|c|c|c|c|c|}
\hline Sample & $\begin{array}{c}\mathrm{S}_{\mathrm{BET}} \\
\left(\mathrm{m}^{2} \mathrm{~g}^{-1}\right)\end{array}$ & $\begin{array}{c}\mathrm{V}_{\text {total }}{ }^{\mathrm{a}} \\
\left(\mathrm{cm}^{3} \mathrm{~g}^{-1}\right)\end{array}$ & $\begin{array}{c}\mathrm{V}_{\text {meso }} \\
\left(\mathrm{cm}^{3} \mathrm{~g}^{-1}\right)\end{array}$ & $\begin{array}{c}V_{\text {micro }}{ }^{b} \\
\left(\mathrm{~cm}^{3} \mathrm{~g}^{-1}\right)\end{array}$ \\
\hline CNTs & 272 & 0.68 & 0.63 & 0.05 \\
\hline N-CNT1 & 200 & 0.45 & 0.41 & 0.04 \\
\hline N-CNT2 & 172 & 0.45 & 0.42 & 0.03 \\
\hline \multicolumn{5}{|c|}{${ }^{\mathrm{a}}$ Total pore volume obtained by the QSDFT method } \\
\hline \multicolumn{5}{|c|}{${ }^{\mathrm{b}}$ Volume of pores $<2 \mathrm{~nm}$ determined through the QSDFT method } \\
\hline
\end{tabular}



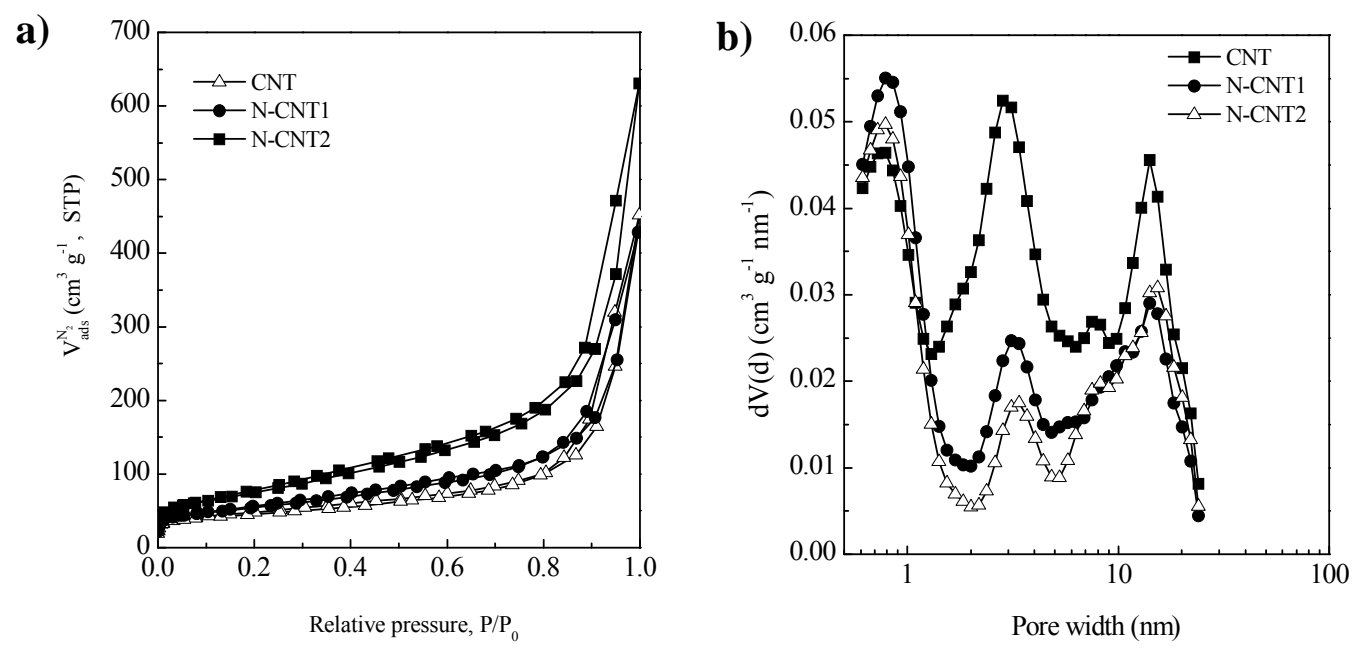

Figure 3. (a) $\mathrm{N}_{2}$ adsorption isotherms of the original CNTs and N-doped carbon / CNTs composites; and (b) their corresponding NLDFT PSDs.

\section{Electrochemical characterization}

Electrochemical testing of the $\mathrm{N}$-doped carbon nanotubes as electrodes in supercapacitors was performed in $1 \mathrm{M} \mathrm{H}_{2} \mathrm{SO}_{4}$. Cyclic voltammograms in a 2-electrode cell are depicted in Figure 4a and 4b. Perfect square-shaped CVs can be observed for all the materials, even for high sweep rates such as $100 \mathrm{mV} \mathrm{s}^{-1}$, which indicates a fast charge propagation. Additionally, a clear increase in the specific capacitance is observed after N-doping; the higher the $\mathrm{N}$ content, the higher the specific capacitance of the electrode. Since N-doping of the carbon nanotubes led to a decrease in the specific surface area from $272 \mathrm{~m}^{2} \mathrm{~g}^{-1}$ to $200 \mathrm{~m}^{2} \mathrm{~g}^{-1}$ for N-CNT1 and $172 \mathrm{~m}^{2} \mathrm{~g}^{-1}$ for N-CNT2, the change in the specific capacitance per unit of surface area is more remarkable, with values increasing from $8 \mu \mathrm{F} \mathrm{cm} \mathrm{cm}^{-2}$ for CNT to 24 and $32 \mu \mathrm{F} \mathrm{cm}{ }^{-2}$ for N-CNT1 and N-CNT2 respectively. Similar enhancement of the capacitance has been previously reported for Ndoped/CNT composites, although with much higher nitrogen contents $(7-14 \mathrm{wt} . \%)$. ${ }^{14,15}$ The advantages of the present synthesis method are the renewable nature of the N-dopant, the environmentally friendly character of the process, and the superficial nature of the coating with $\mathrm{N}$-doped carbon, which ensures quick access to the redox groups. 

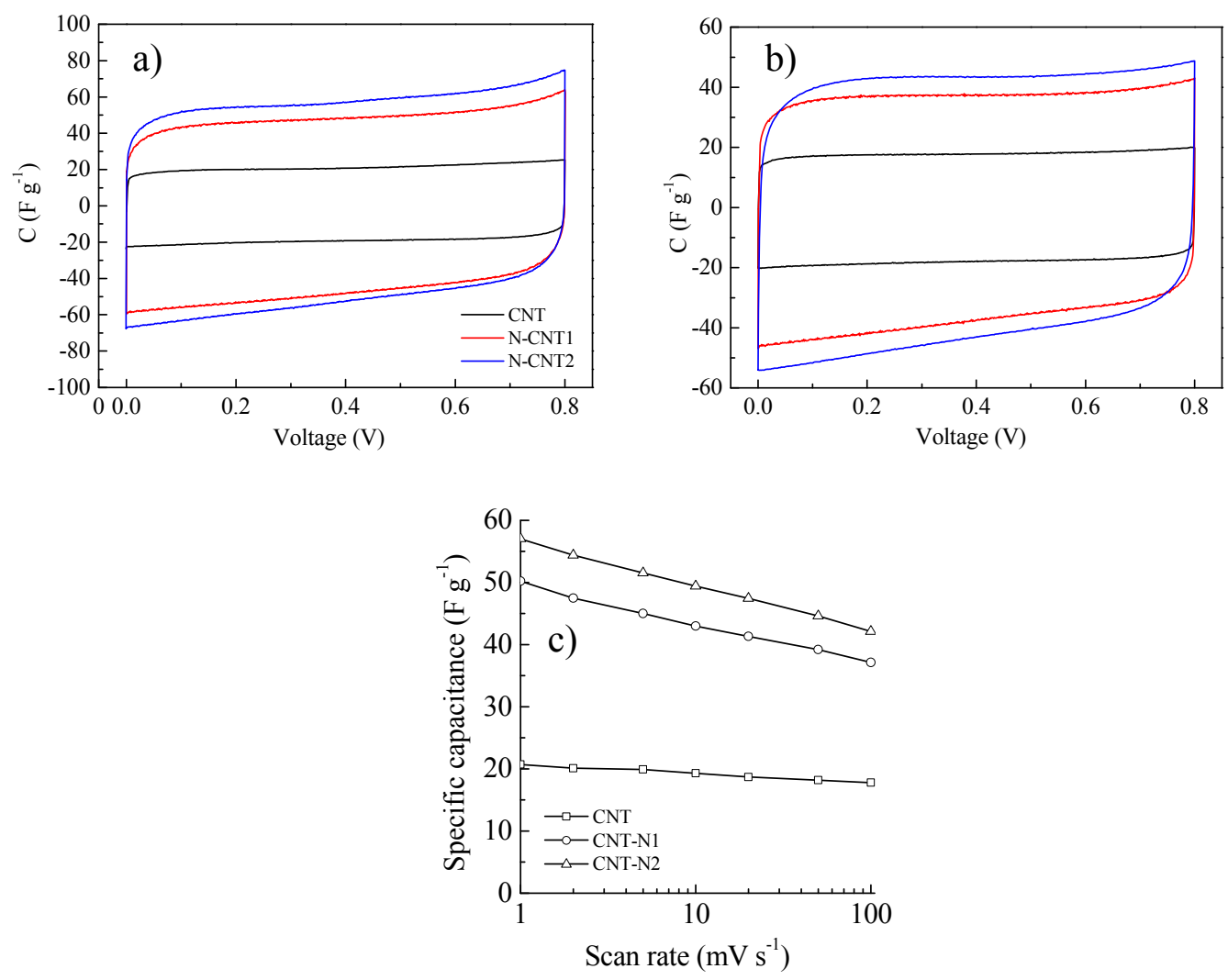

Figure 4. (a) and (b) Cyclic voltammograms in $1 \mathrm{M} \mathrm{H}_{2} \mathrm{SO}_{4}$ at scan rates of $2 \mathrm{mV} \mathrm{s}^{-1}$ and 100 $\mathrm{mV} \mathrm{s}^{-1}$ respectively and (c) capacitance retention with the increase of the scan rate.

Taking into account that the PSD of all the materials is similar, as already discussed, we can assume that the double-layer capacitance contribution for the N-carbon coated CNT is $0.08 \mu \mathrm{F} \mathrm{m}^{-2}$, the value obtained for the un-doped material, although it should be pointed out that improved wettability is observed after $\mathrm{N}$-doping, which may increase the EDL capacitance. The higher surface hydrophobicity of the un-doped sample was also confirmed by the affinity to adsorb water and benzene of the samples (see Figure S1 in Supporting Information). The mass increase after exposure to water vapor was 3 times higher for N-CNT1 (ca. 20 wt.\%) than for CNT (ca. 6 wt.\%), indicating that the former is much more hydrophilic than the latter (hence, wettability is enhanced). Then, the pseudocapacitance contribution could be estimated as $16 \mu \mathrm{F} \mathrm{cm}^{-2}(67 \%)$ and $24 \mu \mathrm{F} \mathrm{cm}^{-2}$ (75\%) for N-CNT1 (1.8 wt.\% N) and N-CNT2 (2.5 wt.\% N) respectively. It can be seen in Figure $4 \mathrm{c}$ that the capacitance retention of pristine CNT with the increase of the sweep rate is higher than that of N-CNT-1 and N-CNT-2. Nevertheless, the rate capability of $\mathrm{N}$-doped carbon nanotubes is excellent, with a decrease of only $20 \%$ for a high sweep rate of $100 \mathrm{mV} \mathrm{s}^{-1}$. As the porous features of all the materials are similar, this larger sweep-rate dependence for the N-doped CNT may be attributed to the slower redox processes in comparison to the fast formation of the double-layer. ${ }^{26}$ 
Three-electrode cell measurements were also performed on the sample N-CNT2 since this material showed the highest contribution of pseudocapacitance. The occurrence of faradaic redox processes on carbon electrodes is usually more evident in the three-electrode configuration, although in the case of nitrogen groups, the redox peaks are very often not welldefined. ${ }^{27}$ The results are depicted in Figure 5. A broad ill-defined hump spreading over a wide potential range (from -0.6 and $\sim 0 \mathrm{~V}$ vs. $\mathrm{Hg} / \mathrm{Hg}_{2} \mathrm{SO}_{4}$ ) can be observed in both the cathodic and anodic sweeps; the voltammograms are similar to those of other $\mathrm{N}$-doped carbon materials reported in the literature. ${ }^{27-28}$ These poorly shaped waves can be ascribed to the redox transitions of pyridinic groups (identified by XPS) according to the following reaction ${ }^{15,29-31}$ :<smiles>CC1=Cc2cc3ncc4c(C)ccc5c4C4(C(=C1)C=CC=C4C(C)C=3)n25</smiles>

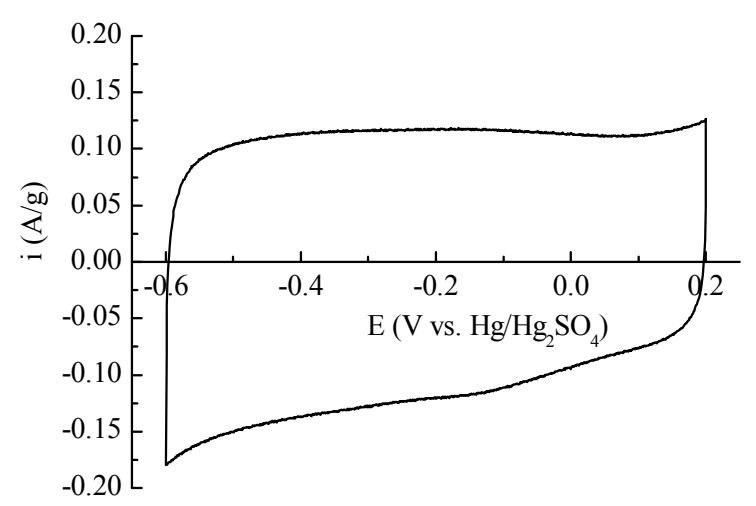

Figure 5. Three-electrode cyclic voltammogram at a weep rate of $2 \mathrm{mV} \mathrm{s}^{-1}$.

It should be noted that $C_{2 E, C V}^{s p}$, the specific capacitance for a single electrode evaluated from the 2-electrode $\left(\sim 54 \mathrm{~F} \mathrm{~g}^{-1}\right.$ at $\left.2 \mathrm{mV} \mathrm{s}^{-1}\right)$ is very close to the value obtained in the 3-electrode configuration, $C_{3 E, C V}^{s p}\left(56 \quad \mathrm{~F}^{-1}\right.$ at $\left.2 \mathrm{mV} \mathrm{s}^{-1}\right)$, which suggest full exploitation of pseudocapacitance phenomena in the 2-electrode cell.

Galvanostatic charge/discharge experiments were also conducted in the 2-electrode system as it is the test which provides the best representation of the real operation of a supercapacitor. As an example, a representative charge/discharge cycle for CNT and N-CNT2 at a current density of $0.1 \mathrm{~A} \mathrm{~g} \mathrm{~g}^{-1}$ is shown in Figure 6a. It can be seen that whereas for CNT a constant slope is 
obtained, reflecting ideal double-layer capacitor behavior, for N-CNT2 (and also N-CNT1) clear deviations from the linearity are registered in the shape of the charge/discharge branches, which further indicates the presence of redox processes in the N-doped CNT. Rate capability, a key parameter for supercapacitors, which are aimed for pulse-power applications, is depicted in Figure 6b. For both N-doped carbon nanotubes, capacitance retention is very good, a decrease of only up to $\sim 30 \%$ being registered for a large current density of $20 \mathrm{~A} \cdot \mathrm{g}^{-1}$. Additionally, negligible IR drop (about half of that observed for CNTs) can be observed for the N-doped CNTs even for that high current density, as shown in Figure 6c. This may be ascribed to a better electron transport due to the quaternary-N. ${ }^{14,} 27$ This combination of low ESR and large capacitance retention leads to Ragone plots with almost no trade-off, as depicted in Figure 6d. Therefore, these $\mathrm{N}$ - carbon coated nanotubes are able to provide virtually the same energy under any operational conditions. Furthermore, it should be pointed out that after a low N-doping (i.e. $\sim 2 \mathrm{wt} . \%$ ), the amount of energy stored is doubled.
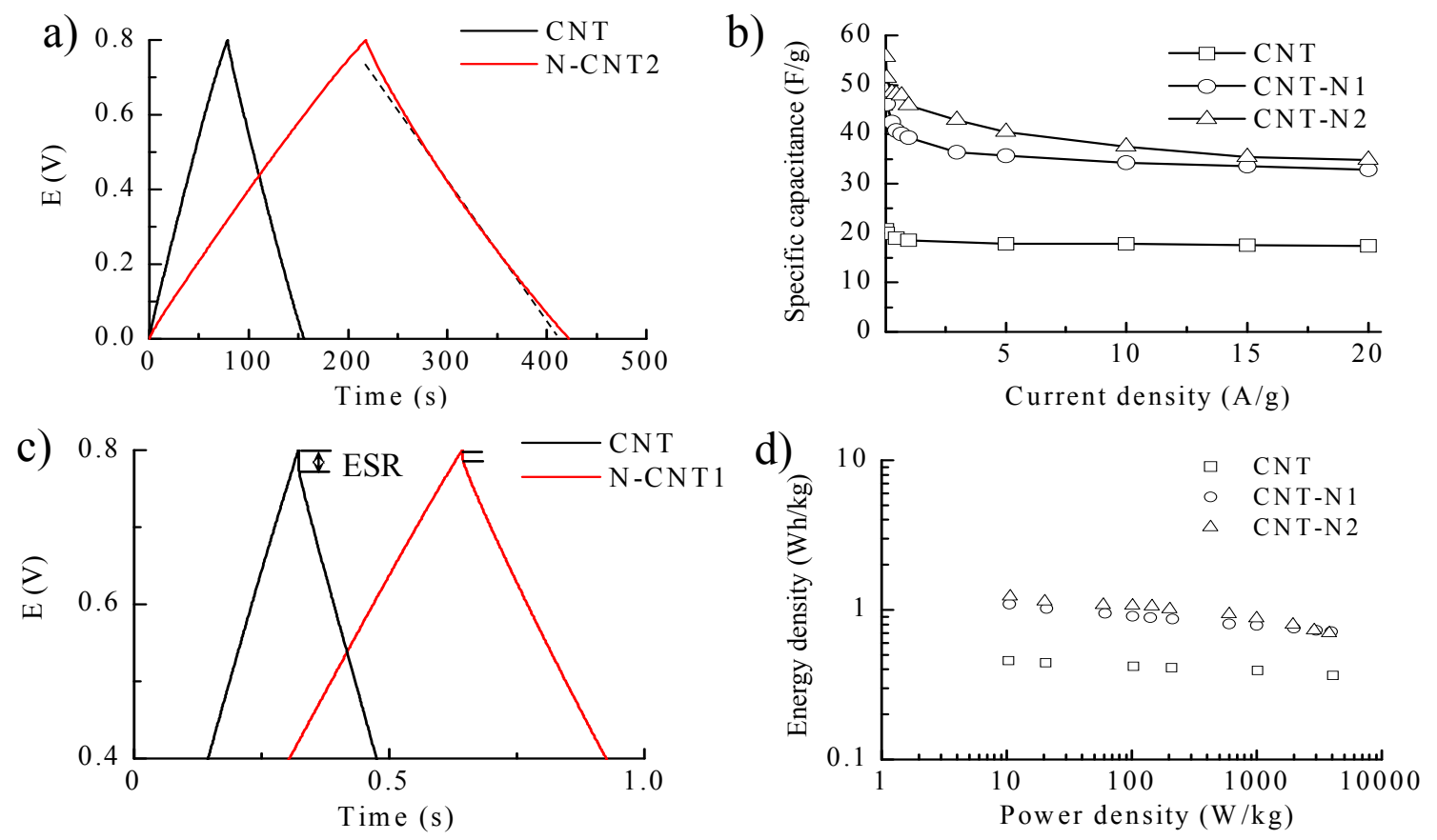

Figure 6. (a) Charge/discharge cycle at $0.1 \mathrm{~A} \mathrm{~g} \mathrm{~g}^{-1}$ for CNT and N-CNT2, (b) capacitance retention with the increase of the current density, (c) charge/discharge cycle at $20 \mathrm{~A} \mathrm{~g}^{-1}$ for CNT and N-CNT1, and (d) Ragone plot.

The last parameter which was studied was long-term stability under charge/discharge cycling at both low and high current densities, i.e. 0.5 and $10 \mathrm{~A} \mathrm{~g}^{-1}$. Even though redox reactions are normally detrimental for the long-term stability of supercapacitors as they are associated to selfdischarge and leakage current, ${ }^{32}$ it can be seen in Figure 7 that the cycling performance of these 
$\mathrm{N}$-containing nanotubes is very stable, even for high current densities. Thus, a decrease of only $3 \%$ is registered for both $\mathrm{N}$-carbon coated CNTs at $0.5 \mathrm{~A} \mathrm{~g}^{-1}$ (after 500 cycles), and 4 and $6 \%$ decrease at $10 \mathrm{~A} \mathrm{~g}^{-1}$ (after 10000 cycles) for N-CNT1 and N-CNT2 respectively.
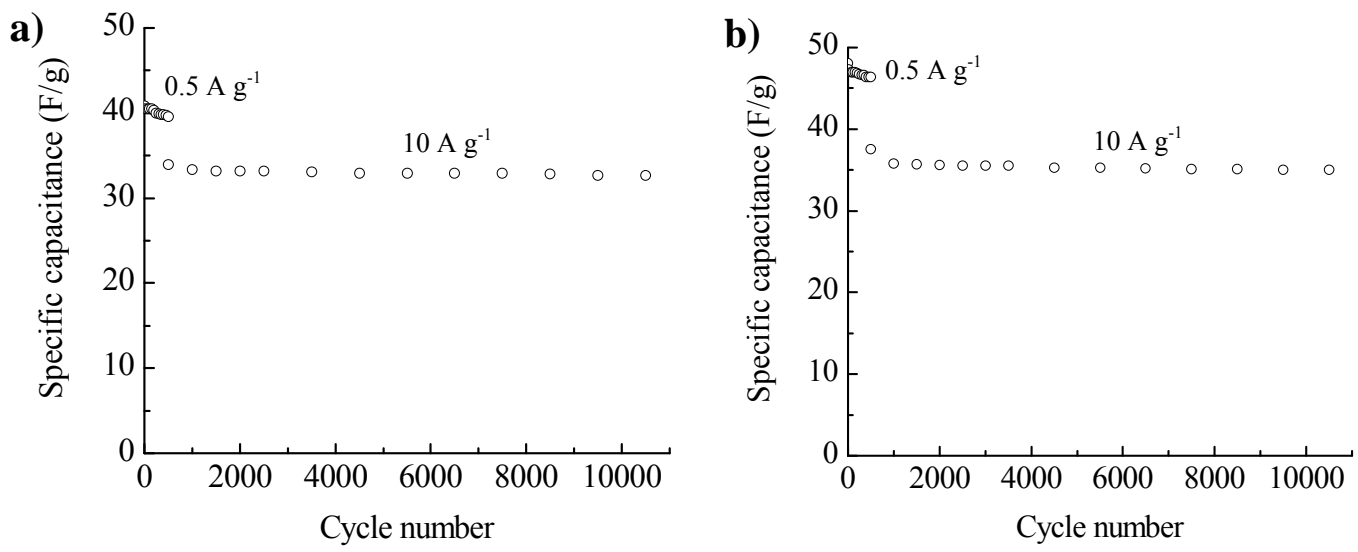

Figure 7. Long-term stability under cycling at low $\left(0.5 \mathrm{~A} \mathrm{~g}^{-1}\right)$ and high $\left(10 \mathrm{~A} \mathrm{~g}^{-1}\right)$ current densities of a) N-CNT1 and b) N-CNT2.

\section{Conclusions}

This work shows the successful surface coating of carbon nanotubes with a layer of N-doped carbon through an environmentally friendly process such as hydrothermal carbonization using a sustainable N-dopant (i.e. glucosamine). By controlling the amount of glucosamine added, it is possible to tune the $\mathrm{N}$ content of the composites N-doped carbon /CNT carbon. Owing to the non-porous nature of the $\mathrm{N}$-doped carbon layer incorporated, the textural properties of the composites decrease. In spite of that, the N-doped carbon / CNT composites exhibit higher specific capacitances $\left(\sim 50-60 \mathrm{~F} \mathrm{~g}^{-1}\right)$ than bare CNTs $\left(\sim 20 \mathrm{~F} \mathrm{~g}^{-1}\right)$. Indeed, the energy stored by the device doubles after $\mathrm{N}$-doping, maintaining excellent rate capability (i.e. power performance) and long-term stability. It has been thereby shown that surface N-coating of carbon nanotubes is a powerful technique for increasing CNTs capacitance through pseudocapacitance phenomena.

\section{ASSOCIATED CONTENT}

\section{Supporting Information}

Analysis of the affinity to adsorb water and benzene of the raw CNTs and the composite Ndoped carbon/CNT. This material is available free of charge via the Internet at http://pubs.acs.org. 


\section{Acknowledgements}

This research work was supported by Spanish MINECO (MAT2012-31651 and CTM201123378). M.S. acknowledges the award of the Ramón y Cajal contract.

\section{References}

(1) Zhang, L. L.; Zhao, X. S., Carbon-based materials as supercapacitor electrodes. Chemical Society reviews 2009, 38 (9), 2520-31.

(2) Xing, W.; Qiao, S. Z.; Ding, R. G.; Li, F.; Lu, G. Q.; Yan, Z. F.; Cheng, H. M., Superior electric double layer capacitors using ordered mesoporous carbons. Carbon 2006, 44 (2), 216224.

(3) Elzbieta Frackowiak; Beguin, F., Carbon materials for the electrochemical storage of energy in capacitors.pdf. Carbon 2001, 39, 937.

(4) Li, L.; Liu, E.; Shen, H.; Yang, Y.; Huang, Z.; Xiang, X.; Tian, Y., Charge Storage Performance of Doped Carbons Prepared from Polyaniline for Supercapacitors. . J. Solid State Electron 2011, 15, 175-182.

(5) Jeong, H. M.; Lee, J. W.; Shin, W. H.; Choi, Y. J.; Shin, H. J.; Kang, J. K.; Choi, J. W., Nitrogen-Doped Graphene for High- Performance Ultracapacitors and the Importance of Nitrogen-Doped Sites at Basal Planes. Nano Lett 2011, 11, 2472.

(6) Guo, H.; Gao, Q., Boron and Nitrogen Co-doped Porous Carbon and Its Enhanced Properties as Supercapacitor. J. Power Sources 2009, 186, 551-556.

(7) Kim, N. D.; Kim, W.; Joo, J. B.; Oh, S.; Kim, P.; Kim, Y.; Yi J, Electrochemical Capacitor Performance of N-Doped Mesoporous Carbons Prepared by Ammoxidation. J. Power Sources 2008, 180, 671-675.

(8) Sevilla, M.; Yu, L.; Fellinger, T. P.; Fuertes, A. B.; Titirici, M.-M., Polypyrrole-derived mesoporous nitrogen-doped carbons with intrinsic catalytic activity in the oxygen reduction reaction. RSC Adv. 2013, 3 (25), 9904-9910.

(9) Zhao, L.; Fan, L. Z.; Zhou, M. Q.; Guan, H.; Qiao, S.; Antonietti, M.; Titirici, M. M., Nitrogen-containing hydrothermal carbons with superior performance in supercapacitors. Adv Mater 2010, 22 (45), 5202-6.

(10) Frackowiak, E.; Méténier, K.; Pellenq, R.; Bonnamy, S.; Béguin, F., Capacitance properties of carbon nanotubes. AIP Conference Proceedings 1999, 486 (1), 429-432.

(11) Futaba, D. N.; Hata, K.; Yamada, T.; Hiraoka, T.; Hayamizu, Y.; Kakudate, Y.; Tanaike, O.; Hatori, H.; Yumura, M.; lijima, S., Shape-engineerable and highly densely packed single-walled carbon nanotubes and their application as super-capacitor electrodes. Nat Mater 2006, 5 (12), 987-994.

(12) Frackowiak, E.; Jurewicz, K.; Delpeux, S.; Béguin, F., Nanotubular materials for supercapacitors. J. Power Sources 2001, 97-98 (0), 822-825.

(13) Chen, G. Z.; Shaffer, M. S. P.; Coleby, D.; Dixon, G.; Zhou, W.; Fray, D. J.; Windle, A. H., Carbon Nanotube and Polypyrrole Composites: Coating and Doping. Adv. Mater. 2000, 12 (7), 522-526.

(14) Béguin, F.; Szostak, K.; Lota, G.; Frackowiak, E., A Self-Supporting Electrode for Supercapacitors Prepared by One-Step Pyrolysis of Carbon Nanotube/Polyacrylonitrile Blends. Adv. Mater. 2005, 17 (19), 2380-2384.

(15) Lota, G.; Lota, K.; Frackowiak, E., Nanotubes based composites rich in nitrogen for supercapacitor application. Electrochemistry Communications 2007, 9 (7), 1828-1832.

(16) Yun, Y. S.; Park, H. H.; Jin, H.-J., Pseudocapacitive Effects of N-Doped Carbon Nanotube Electrodes in Supercapacitors. Materials 2012, 5 (7), 1258-1266. 
(17) Li, L.-X.; Tao, J.; Geng, X.; An, B.-G., Preparation and Supercapacitor Performance of Nitrogen-Doped Carbon Nanotubes from Polyaniline Modification. Acta Physico-Chimica Sinica 2013, 29 (1), 111-116.

(18) Antonietti, M.; Titirici, M.-M., Coal from carbohydrates: The "chimie douce" of carbon. Comptes Rendus Chimie 2010, 13 (1-2), 167-173.

(19) Hu, Y. S.; Demir-Cakan, R.; Titirici, M. M.; Muller, J. O.; Schlogl, R.; Antonietti, M.; Maier, J., Superior storage performance of a Si@SiOx/C nanocomposite as anode material for lithium-ion batteries. Angew Chem Int Ed Eng/ 2008, 47 (9), 1645-9.

(20) Zhao, L.; Fan, L. Z.; Zhou, M. Q.; Guan, H.; Qiao, S. Y.; Antonietti, M.; Titirici, M. M., Nitrogen-Containing Hydrothermal Carbons with Superior Performance in Supercapacitors. Adv. Mater. 2010, 22 (45), 5202-5206.

(21) Ikeda, S.; Tachi, K.; Ng, Y. H.; Ikoma, Y.; Sakata, T.; Mori, H.; Harada, T.; Matsumura, M., Selective Adsorption of Glucose - Derived Carbon Precursor on Amino-Functionalized Porous Silica for Fabrication of Hollow Carbon Spheres with Porous Walls. Chem. Mater. 2007, 19 (17), 4335-4340.

(22) Yu, L. H.; Brun, N.; Sakaushi, K.; Eckert, J.; Titirici, M. M., Hydrothermal nanocasting: Synthesis of hierarchically porous carbon monoliths and their application in lithium-sulfur batteries. Carbon 2013, 61, 245-253.

(23) Titirici, M.-M.; White, R. J.; Falco, C.; Sevilla, M., Black perspectives for a green future: hydrothermal carbons for environment protection and energy storage. Energy Environ. Sci. 2012, 5 (5), 6796-6822.

(24) Pels, J. R.; Kapteijn, F.; Moulijn, J. A.; Zhu, Q.; Thomas, K. M., Evolution of nitrogen functionalities in carbonaceous materials during pyrolysis. Carbon 1995, 33 (11), 1641-1653.

(25) Schmiers, H.; Friebel, J.; Streubel, P.; Hesse, R.; Köpsel, R., Change of chemical bonding of nitrogen of polymeric N-heterocyclic compounds during pyrolysis. Carbon 1999, 37 (12), 1965-1978.

(26) Gu, W.; Sevilla, M.; Magasinski, A.; Fuertes, A. B.; Yushin, G., Sulfur-containing activated carbons with greatly reduced content of bottle neck pores for double-layer capacitors: a case study for pseudocapacitance detection. Energy Environ. Sci. 2013, 6 (8), 2465-2476.

(27) Hulicova-Jurcakova, D.; Seredych, M.; Lu, G. Q.; Bandosz, T. J., Combined Effect of Nitrogen- and Oxygen-Containing Functional Groups of Microporous Activated Carbon on its Electrochemical Performance in Supercapacitors. Adv. Funct. Mater. 2009, 19 (3), 438-447.

(28) Hulicova-Jurcakova, D.; Kodama, M.; Shiraishi, S.; Hatori, H.; Zhu, Z. H.; Lu, G. Q., Nitrogen-Enriched Nonporous Carbon Electrodes with Extraordinary Supercapacitance. Adv. Funct. Mater. 2009, 19 (11), 1800-1809.

(29) Frackowiak, E., Carbon materials for supercapacitor application. Phys. Chem. Chem. Phys. 2007, 9 (15), 1774-1785.

(30) Lee, Y.-H.; Chang, K.-H.; Hu, C.-C., Differentiate the pseudocapacitance and doublelayer capacitance contributions for nitrogen-doped reduced graphene oxide in acidic and alkaline electrolytes. J. Power Sources 2013, 227 (0), 300-308.

(31) Wang, D.-W.; Li, F.; Yin, L.-C.; Lu, X.; Chen, Z.-G.; Gentle, I. R.; Lu, G. Q.; Cheng, H.-M., Nitrogen-Doped Carbon Monolith for Alkaline Supercapacitors and Understanding NitrogenInduced Redox Transitions. Chemistry - A European Journal 2012, 18 (17), 5345-5351.

(32) Kierzek, K.; Frackowiak, E.; Lota, G.; Gryglewicz, G.; Machnikowski, J., Electrochemical capacitors based on highly porous carbons prepared by $\mathrm{KOH}$ activation. Electrochim. Acta 2004, 49 (4), 515-523. 


\section{FOR TABLE OF CONTENTS USE ONLY}

Surface modification of CNTs with N-doped carbon: an effective way of enhancing its performance in supercapacitors

Marta Sevilla*, ${ }^{a}$ Linghui Yu, ${ }^{\mathrm{b}}$ Li Zhao, ${ }^{\mathrm{c}}$ Conchi O. Ania, ${ }^{\mathrm{a}}$ Maria-Magdalena Titiricic*d

A sustainable approach based on the hydrothermal carbonization process has been used for the preparation of $\mathrm{CNT} / \mathrm{N}$-doped carbon composites with enhanced supercapacitor performance

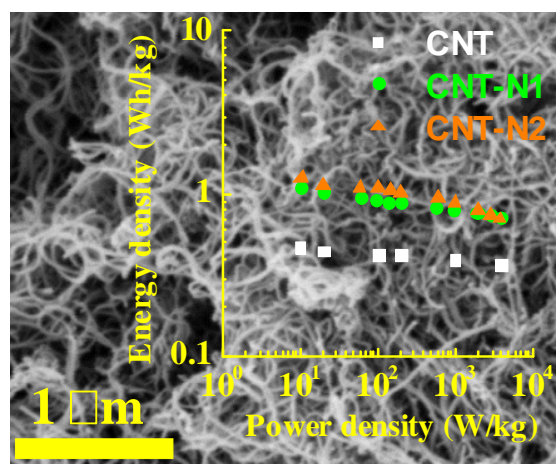

